\title{
Retrogressive shear band propagation and spreading failure criteria for submarine landslides
}

\author{
A. M. PUZRIN*, T. E. GRAY† and A. J. HILL†
}

\begin{abstract}
The paper proposes a mechanism of submarine spreading failures, which combines retrogressive shear band propagation (SBP) with a series of active block failures in the 'stable' zone of the slope, where the gravitational shear stress is smaller than the residual shear strength. Gradual downhill removal of the failed material causes a decrease in the supporting earth pressure, leading to the progressive uphill propagation of the shear band (termed here 'retrogressive' SBP) and uniquely determining its length, which can be linked to the dimensions of the spreading failure block mechanisms. Two conjugate energy balance based criteria have been formulated for the spreading failure, in terms of either the critical depth of the sliding surface or the critical drop of the failed seabed level. Both criteria have been validated against the observed phenomena (presence and absence of the evidence of spreading failure for different landslide depths and a step in the sliding surface) in palaeo-landslide examples from the Caspian Sea. The proposed framework provides closed-form criteria, which could be incorporated into a geographical information system based deterministic and probabilistic stability analysis framework for assessment of spreading failure risks in submerged slopes across offshore developments.
\end{abstract}

KEYWORDS: failure; geomorphology; landslides; offshore engineering; slopes

\section{INTRODUCTION}

\section{Modelling of spreading failures}

Underwater landslides often exhibit features of spreading failure, where downslope removal of material causes unloading of the temporary stable slope, with blocks of soil eventually experiencing active failure, detaching and moving downslope. This unloads upper portions of the slope, which in turn reach active failure state, causing new spreading failures to occur (e.g. Haflidason et al., 2004; Masson et al., 2006; Vanneste et al., 2014).

Figure 1(a), after Gray et al. (2015), shows the seafloor bathymetry over a section of the Azeri-Chirag-Gunashli (ACG) oil field, which is being developed pursuant to the 'Agreement on the joint development and production sharing for the Azeri and Chirag fields and the deep water portion of the Gunashli field in the Azerbaijan sector of the Caspian Sea' dated 20 September 1994. Two palaeo-landslides are visible at the seabed and in seismic cross-section (see Gray et al. (2015) for further details regarding the geophysical data). The larger failure visible on three-dimensional highresolution seismic data is MM700, a 'mega' scale landslide with a deposit that stretches far out into the South Caspian basin (see Richardson et al. (2011) for more details). MM700 has been dated using biostratigraphic and radiometric analysis to approximately 40000 years BP, and is now draped by younger sediments that thin towards its head scarp to the north (Fig. 1(b)). A key feature of the upslope part of MM700 is the presence of blocks exhibiting a horst and graben structure. The blocks are interpreted as a retrogressive spreading zone, typical of long and thin 'lateral spread' landslides (Varnes, 1978).

Manuscript received 24 September 2015; revised manuscript accepted 29 September 2016. Published online ahead of print 16 November 2016.

Discussion on this paper closes on 1 July 2017, for further information see $\mathrm{p}$. ii.

* Institute for Geotechnical Engineering, ETH Zurich, Zurich, Switzerland.

$\dagger$ East Point Geo Ltd, Norwich, Norfolk, UK.

+ BP Exploration, Sunbury, UK.
A smaller failure (MM900) occurs in the drape above MM700 and is clearly visible on present-day bathymetric data (Fig. 1(a)). MM900 is visible on sub-bottom profiler data and is a complex failure with a mechanism described in detail by Gray et al. (2015) (Fig. 1(a)). The main point relevant to the present study is the absence of a retrogressive spreading zone upslope of the steep initiating slope. MM900 has been dated using biostratigraphic and radiometric analysis to approximately 5000 years BP.

Earlier studies (e.g. Odenstad, 1951; Carson, 1977; Kvalstad et al., 2005) have identified on- and offshore spreading failures and explored their mechanisms mainly focusing on the disintegration of the sliding layer into horsts and grabens. At the same time, other studies have explored analytically (Bjerrum, 1967; Palmer \& Rice, 1973; Quinn et al., 2011, 2012) or numerically (Lo, 1972; Lo \& Lee, 1973; Potts et al., 1990; Kovacevic et al., 2004, 2007; Locat et al., 2013) the phenomena of a shear band propagating uphill parallel to the slope as a result of the slope unloading at the toe. The above studies have focused on onshore slope failures in sensitive or overconsolidated clays, with the strainsoftening shear behaviour of the soil being identified as a critical condition for the shear band propagation (SBP).

Locat et al. (2011, 2013) and Quinn et al. $(2011,2012)$ were the first to propose linking the spreading failures with the uphill SBP for onshore landslides in sensitive clays. In their work, failure is initiated near the toe of the slope and propagates sub-horizontally into the intact deposit, reducing subhorizontal stresses in the deposit. When the sub-horizontal stress approaches the active resistance of the soil mass above the shear zone, the sliding layer may break into blocks of more or less intact material having horst and graben shapes. As failure propagates inside the deposit, a larger zone may reach active failure, leading to the formation of a succession of horst and graben blocks. While correctly concluding that onshore spreading failures in sensitive clays are caused by the repetitive succession of the uphill SBP and active failure of the soil mass above the shear band, Locat et al. $(2011,2013)$ and Quinn et al. (2011, 2012) have not provided the quantitative criteria linking the SBP conditions with the active failure block mechanisms. 




(a)

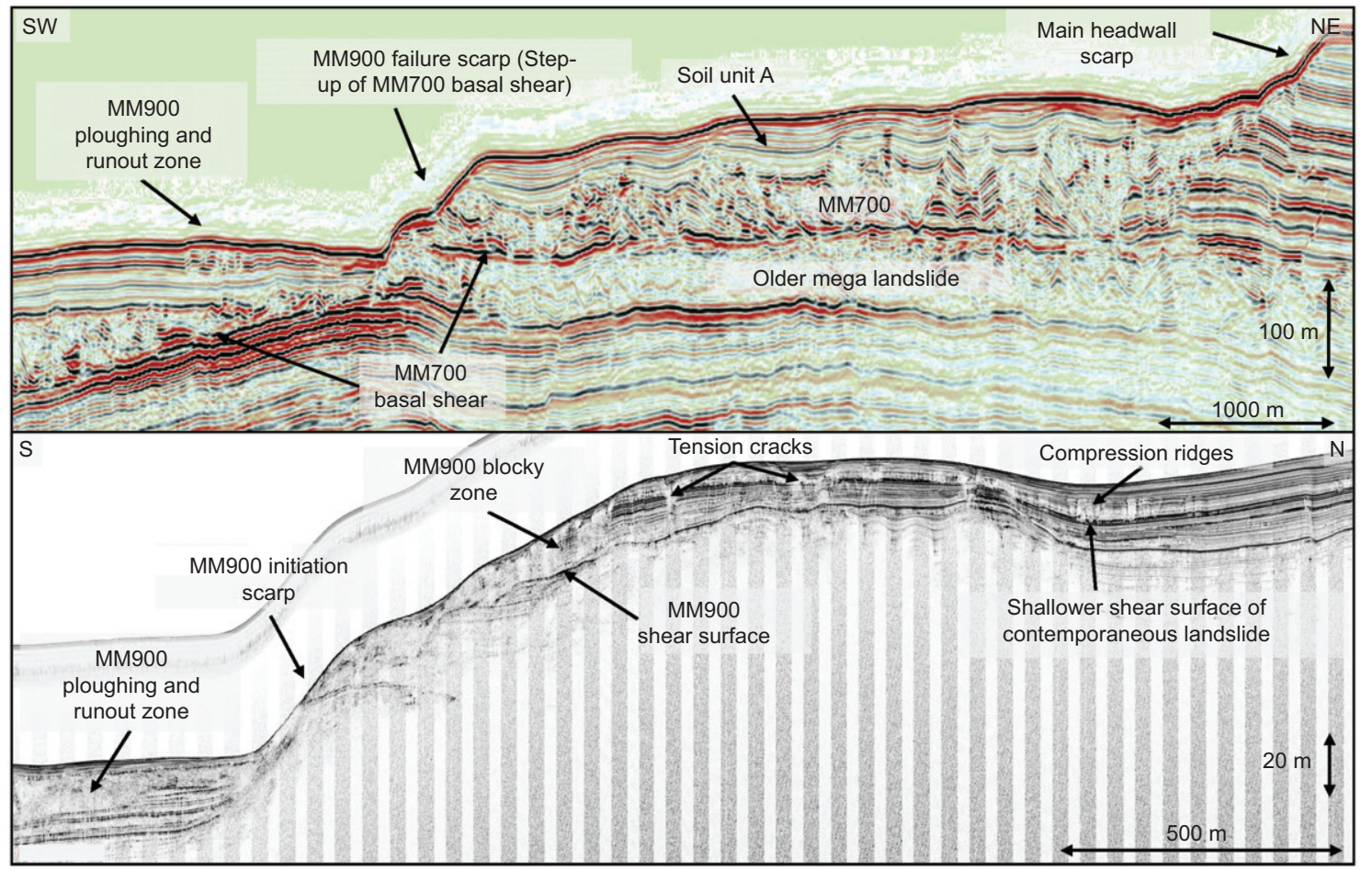

(b)

Fig. 1. A section of the Caspian Sea Azeri basin, after Gray et al. (2015), published with permission of OTC: (a) bathymetry of the studied seafloor section and its location (inset in the top right corner) within the ACG oil field (AUV, autonomous underwater vehicle; 3DHR, threedimensional high resolution (seismic)); (b) geophysical downslope cross-section

The present paper deals with spreading failures in submarine landslides, where strain-softening behaviour has been observed in normally to slightly overconsolidated deposits. Its purpose is to facilitate understanding and prediction of spreading failure phenomena by establishing quantitative relationships between the active failure block models of the type proposed by Kvalstad et al. (2005) and the SBP models based on the energy balance approaches of Palmer \& Rice
(1973) and Puzrin \& Germanovich (2005). As shown below, it is desirable to derive these relationships analytically.

Shear band propagation approach to slope stability

The SBP approach (Palmer \& Rice, 1973; Puzrin \& Germanovich, 2005; Viesca \& Rice, 2012) provides criteria allowing an initial shear band (a localised zone of intense 
shearing, where the shear stress exceeds the peak shear strength) to propagate into portions of the sliding surface where the shear stress is lower than the peak shear strength but exceeds the residual strength. As such, it is feasible for an initial weak zone to grow, meaning that only a portion of the failure surface needs to reach the critical conditions for failure, and that local, readily occurring factors can offer a simpler explanation to the often enormous dimensions and common occurrence of submarine landslides in nature.

For the initial weak zone to propagate dynamically parallel to the slope surface, its length should exceed some critical length. The value of this critical length can be defined based on the static analysis using fracture mechanics or the energy balance (slip weakening) criteria (Palmer \& Rice, 1973; Rice, 1973; Puzrin et al., 2004, 2010; Puzrin \& Germanovich, 2005; Quinn et al., 2011, 2012; Dey et al., 2012; Viesca \& Rice, 2012).

Puzrin et al. (2015) developed a simple approach to slope stability analysis of naturally occurring, mild, non-linear slopes through extension of the SBP theory. It has been shown that, under uniform loading in mild slopes with slowly changing gradient and soil properties varying only with depth but not parallel to the slope, an initial weak zone appears in the steepest part of the slope where the combined action of gravity and seismic loads overcomes the degraded peak shear resistance of the soil. If the length of this steepest part is larger than the critical length, the shear band will propagate into the quasi-stable parts of the slope, where the gravitational and seismically induced shear stresses are smaller than the peak but larger than the residual shear strength of the soil. Accounting for the true non-linear slope geometry eliminates the main challenge of the SBP approach - determination of the length of the initial weak zone, because the slope geometry can be readily obtained from submarine site investigations. It also helps to identify conditions for the early arrest of the shear band. The difference in the size of a landslide predicted by limiting equilibrium and SBP approaches can reach orders of magnitude, potentially providing an explanation for the immense dimensions of many observed submarine landslides that may be caused by local factors acting over a limited portion of the slope.

The resulting criteria for the SBP and arrest were calibrated against data from Caspian Sea palaeo-landslides (Gray et al., 2015). Being derived in a closed form, they could be incorporated into any geographical information system (GIS) based deterministic and probabilistic stability analysis (PSA) framework (Dimmock et al., 2012; Rushton et al., 2015). Within this context, the objective of this paper is to extend the Puzrin et al. (2015) approach to investigate conditions under which the shear band will propagate further uphill, into the stable zone, potentially causing spreading to occur. In order to enable incorporation into a general probabilistic framework, it is highly desirable to derive spreading failure criteria in the closed form, which poses challenges at the outset stage of the problem formulation.

\section{Challenges of the retrogressive $S B P$ analysis}

Although the difference between brittle (unstable) and progressive (stable) failure is relatively well understood in fracture mechanics, there is no clear distinction in the soil mechanics literature. Puzrin \& Germanovich (2005) have demonstrated that one of the advantages of the SBP approach is that it allows for different types of failure to be clearly distinguished. In progressive failure, propagation of the shear band is stable in a sense that it requires work of additional external forces. In brittle failure, propagation of the shear band is unstable and takes place under existing external forces. It follows that uphill SBP, which is sometimes termed a retrogressive SBP and is the one relevant for the spreading failure phenomena, can be either unstable or stable, depending mainly on whether the driving gravitational shear stress is, respectively, larger or smaller than the resisting residual shear strength on the sliding surface. Previous analytical studies have focused mainly on the problem of the shear band propagating in an unstable way (i.e. under existing external forces) uphill from a cut in a slope (Palmer \& Rice, 1973; Quinn et al., 2011, 2012). This shear band propagates into the quasi-stable zone, where the driving force (combination of gravitational shear stress and initial normal pressure in the sliding layer) is larger than the residual shear strength. In most cases this implies that sub-horizontal normal stresses in the sliding body may decrease uphill from the cut, in other words, become tensile, which is not always realistic for soil applications and will not result in the active spreading failure mechanism.

In the analysis by Puzrin \& Germanovich (2005) of the stability of an infinite slope, the problem of tensile normal stresses was addressed, and while the shear band also propagates unstably into the quasi-stable zone down- and uphill once its length exceeds the critical value, the pressures in the sliding body always remain compressive and above the active earth pressure. The uphill propagation, however, terminates when the soil reaches active failure conditions, thus excluding any further possibility of spreading.

It seems that the existing attempts to analytically link uphill SBP to spreading failures have not so far been successful for the same reason: consideration of unstable uphill SBP into the quasi-stable zone, which has to terminate once the pressure in the sliding layer drops to the active pressure. This suggests that the proper approach to the problem of spreading failures should instead consider progressive uphill SBP into the stable zone where the gravitational shear stress is smaller than the residual shear strength. Indeed, within the context of submarine landslides Puzrin et al. (2015) have demonstrated that the shear band, once initiated, will always propagate unstably through the entire quasi-stable zone, eventually causing a slab failure. It follows that the spreading failure can only occur in the stable zone, uphill from the quasi-stable zone, where further SBP will be driven by gradual removal of the slab material at the bottom of the slope. Unloading causes a decrease in the supporting pressure, leading to the progressive uphill propagation of the shear band and uniquely determines its length. Under such conditions the pressures in the sliding body will always remain compressive and will not get below the active earth pressure, allowing the length of the shear band to be linked to dimensions of the spreading failure blocks. In this paper only such progressive, uphill SBP, driven by the removal of material at the bottom of the slope, will be defined as retrogressive SBP, to distinguish it from other types of SBP. The paper presents an analytical solution of the problem of retrogressive SBP, its link to spreading failures and validation against Caspian Sea palaeo-landslide data.

\section{SHEAR BAND PROPAGATION APPROACH TO STABILITY ANALYSIS OF NON-LINEAR SLOPES Slope zonation with respect to shear stress ratio}

For a non-linear slope geometry considered in Fig. 2 (a generalised S-shaped slope represents a broad range of possible monotonic slope shapes), the sliding surface is assumed to be located at the depth $h$ parallel to the slope surface. Strain-softening shear behaviour of the soil is assumed on the sliding surface (Fig. 3), with the undrained shear strength dropping from peak $\tau_{\mathrm{p}}$ to residual $\tau_{\mathrm{r}}$. Both strength values are assumed to be proportional to effective stresses. Within the sliding body, the soil behaviour is elasto-plastic (Fig. 4) with 


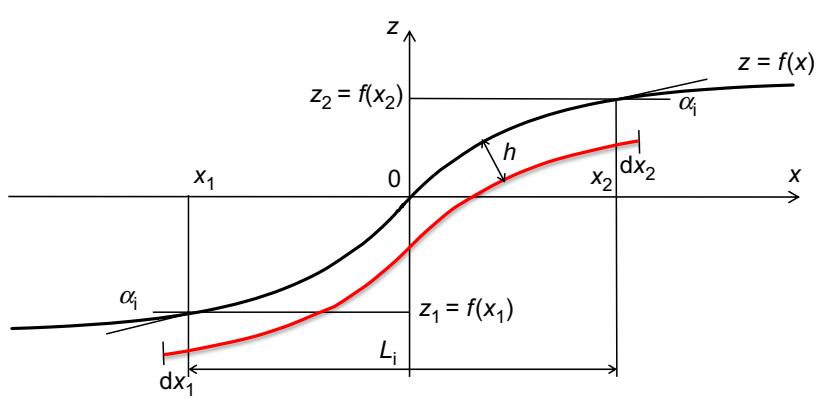

Fig. 2. Shear band propagation in a curved slope

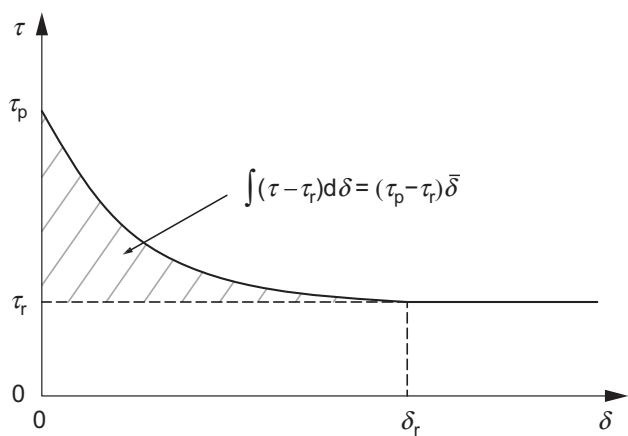

Fig. 3. Stress-strain behaviour in the shear band

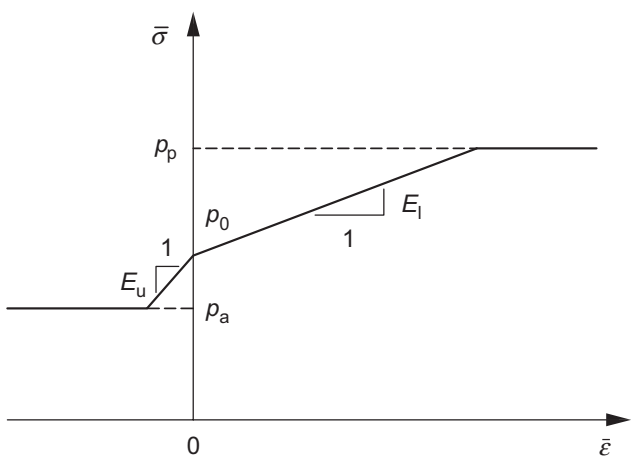

Fig. 4. Stress-strain behaviour in the sliding layer

different plane strain deformation moduli $\left(E_{1}\right.$ and $\left.E_{\mathrm{u}}\right)$ and failure pressures $\left(p_{\mathrm{p}}\right.$ and $\left.p_{\mathrm{a}}\right)$ in loading and unloading, respectively. Seismic slope stability analysis is performed using a pseudo-static approach with degradation of the shear strength as a result of the cyclic loading.

In the SBP approach, Palmer \& Rice (1973) defined the shear stress ratio for an infinite slope, which is extended here to account for the seismic loading, shear strength degradation and background excess pore water pressures

$$
r=\frac{\tau_{\mathrm{g}}+\tau_{\mathrm{h}}-\tau_{\mathrm{r}}}{\tau_{\mathrm{p}}-\tau_{\mathrm{r}}}=\frac{s\left(\tau_{\mathrm{g}}+\tau_{\mathrm{h}}\right) / \tau_{\mathrm{p}}-1}{s-1}
$$

and allows for identification of unstable $(1 \leq r)$ slopes, quasistable $(0 \leq r<1)$ slopes (where the SBP can take place under certain conditions), and stable $(r<0)$ slopes. Here

$$
s=\frac{\tau_{\mathrm{p}}}{\tau_{\mathrm{r}}}
$$

the ratio between the peak and residual shear strength is referred to as sensitivity

$$
\tau_{\mathrm{g}}=\gamma^{\prime} h \sin \alpha
$$

is the gravitational shear stress $\left(\gamma^{\prime}\right.$ is the submerged unit weight of soil)

$$
\tau_{\mathrm{h}}=k_{\mathrm{h}} \gamma^{\prime} h \cos \alpha=C \frac{a_{\max }}{\boldsymbol{g}} \gamma_{\mathrm{t}} h \cos \alpha
$$

is the pseudo-static earthquake-induced shear stress $\left(\gamma_{\mathrm{t}}\right.$ is the total unit weight of soil; $C$ is the pseudo-static factor; $k_{\mathrm{h}}$ is the pseudo-static coefficient)

$$
\tau_{\mathrm{p}}=k \sigma_{\mathrm{n}}^{\prime}=k \delta_{\mathrm{d}} \gamma^{\prime}\left(1-r_{\mathrm{u}}\right) h \cos \alpha
$$

is the peak undrained shear strength, where $k=0 \cdot 20-0 \cdot 30$ is the undrained shear strength coefficient for normally consolidated sediments, $\delta_{\mathrm{d}}$ is the seismic shear strength degradation index, and $r_{\mathrm{u}}=u_{\mathrm{e}} / \gamma^{\prime} h$ is the normalised excess pore water pressure at the depth $h$. It is assumed that the excess pore water pressure grows linearly with depth, $r_{\mathrm{u}}=$ const, causing flow normal to the slope surface, which is a more conservative assumption than the upward flow. Equations (2) and (5) imply that excess pore water pressures and seismic shear strength degradation affect both the peak and residual shear strength. Equation (1) can be then rewritten as

$$
r=\frac{s \chi\left(\tan \alpha+k_{\mathrm{h}}\right)-1}{s-1}, \quad \text { where } \chi=\frac{1}{\delta_{\mathrm{d}} k\left(1-r_{\mathrm{u}}\right)}
$$

Two earthquake loading factors in equation (6) are: $\delta_{\mathrm{d}}$, the degradation index, and $k_{\mathrm{h}}$, the pseudo-static coefficient. They can be related to the earthquake parameters, $a_{\max }$, the peak horizontal ground acceleration and $M$, the earthquake magnitude (Boulanger and Idriss, 2004). The factor $C$ is recommended for earth dams to be in a range around 0.5 (Hynes-Griffin and Franklin, 1984); for submarine slopes, Dimmock et al. (2012) treated $C$ as a probabilistic value with a standard deviation of 0.08 around a mean of 0.23 (specific values of $C$ depend on the value of the Newmark permanent slope displacement adopted as the initiation of failure). These and other empirical parameters used in equations (1)-(6) can be readily obtained from the results of standard geotechnical field and lab investigations and probabilistic stability analysis performed for offshore developments. An example of a relevant set of parameters is given in this paper for a case study of the Caspian Sea palaeo-landslides.

For a non-linear slope geometry, the main difference with the conventional SBP approach is that the slope angle changes continuously and the shear stress ratio becomes a function of the coordinate $x$

$$
r(x)=\frac{s \chi\left[f^{\prime}(x)+k_{\mathrm{h}}\right]-1}{s-1}
$$

where $z=f(x)$ is the equation of the slope surface in Fig. 2.

The shear stress ratio (equation (7)) is a critical parameter for SBP stability analysis of non-linear submarine slopes. In contrast to the infinite slope case, the unstable $(1 \leq r)$, quasi-stable $(0 \leq r<1)$ and stable $(r<0)$ zones, can be identified within a single non-linear slope. It can be assumed that earthquake loading causes the gravitational and seismic driving forces to overcome the degraded peak shear strength at all the points of the sliding surface where the inclination of the surface exceeds $\alpha_{\mathrm{i}}$ (Fig. 2). This results in the shear stress ratio $r \geq 1$ and formation of the initial shear band of length $L_{\mathrm{i}}$, where the shear strength drops to its residual value $\tau_{\mathrm{r}}$. Under certain conditions (described in the following section) this initial shear band will propagate unstably into the quasi-stable zone with $0 \leq r<1$, and subsequently arrest somewhere within the stable zone of $r<0$.

Shear band propagation and arrest in a curved slope

For a curved slope, Puzrin et al. (2015) showed that the shear band propagates unstably (i.e. under existing external 
forces) once its initial length $L_{\mathrm{i}}$ (Fig. 2) exceeds the critical value

$$
L_{\mathrm{i}} \geq L_{\mathrm{cr}}=\frac{1}{\bar{r}}\left(1+\sqrt{\frac{E_{\mathrm{l}}}{E_{\mathrm{u}}}}\right) \sqrt{\frac{s \chi \cos \alpha_{\mathrm{i}}}{s-1} \frac{2 E_{\mathrm{u}} \bar{\delta}}{\gamma^{\prime}}}
$$

where

$$
\begin{aligned}
& \bar{r}=\frac{s \chi\left\{\left[f\left(x_{2}\right)-f\left(x_{1}\right)\right] /\left[x_{2}-x_{1}\right]+k_{\mathrm{h}}\right\}-1}{s-1} \\
& \bar{\delta}=\frac{\int_{0}^{\delta_{\mathrm{r}}}\left(\tau-\tau_{\mathrm{r}}\right) \mathrm{d} \delta}{\tau_{\mathrm{p}}-\tau_{\mathrm{r}}}
\end{aligned}
$$

and $\delta_{\mathrm{r}}$ is the relative displacement within the shear band at which the residual strength is reached (Fig. 3); $E_{1}$ and $E_{\mathrm{u}}$ are deformation plane strain moduli in loading and unloading, respectively (Fig. 4).

With the growth of the shear band length $L$, the average gravitational shear stress ratio $\bar{r}$ in equation (9) decreases, so that the critical length $L_{\mathrm{cr}}$ in equation (8) increases and can, in principle, exceed the current length of the shear band. Puzrin et al. (2015) have shown that if the shear band starts propagating, it will always reach the boundaries of the quasi-stable zone, as long as the average gravitational shear stress ratio $\bar{r}$ remains positive (always true within the quasi-stable zone, where $r>0$ ). This is, of course, assuming that pseudo-static acceleration, excess pore water pressures and degradation index do not change during the SBP.

In fact, the shear band will propagate even further, into the stable zone. By accounting for the dynamic effects of the SBP, Germanovich et al. (2016) have shown that inertia and wave propagation could extend the final shear band length beyond its static estimates, leading to the shear band arrest criterion of $\bar{r}=0$. This is consistent with the upper bound static estimate (8), according to which, for $\bar{r}=0$, the critical length for unstable SBP becomes infinite.

The important question, however, which the above analysis does not answer is whether the condition $\bar{r}=0$ provides the ultimate limit of the SBP and the corresponding landslide dimensions, or is it possible that after earthquake shaking has ceased, the shear band will propagate further into the uphill stable zone, potentially causing spreading to occur. The following sections investigate possible conditions for such propagation.

\section{SPREADING FAILURE IN THE STABLE ZONE}

Kvalstad et al. (2005) proposed a block mechanism of retrogressive failure (its simplified version given in Fig. 5), driven by the removal of the material at the foot of the semi-infinite slope (Fig. 6). Because in rapid failure the undrained shearing of fine-grained soils can be described by a Tresca type failure criterion, the limit analysis suggests that the failure planes should be inclined by $45^{\circ}$ to a principal axis, assumed below to be parallel to the slope surface. The resulting block mechanism is readily supported by geophysical observations of palaeo-landslides (e.g. Fig. 1). One of the critical assumptions of this mechanism is that the strength of soil at the bottom of the blocks is at its residual value, which is only possible if a shear band propagates parallel to the slope and the maximum length $L_{\mathrm{sb}}$, which the shear band can propagate (for a given drop in the seafloor surface) in the intact layer of the original height $h_{z}$, is larger than the length of the block $L_{3}$ (Fig. 6)

$$
L_{\mathrm{sb}} \geq L_{3}
$$

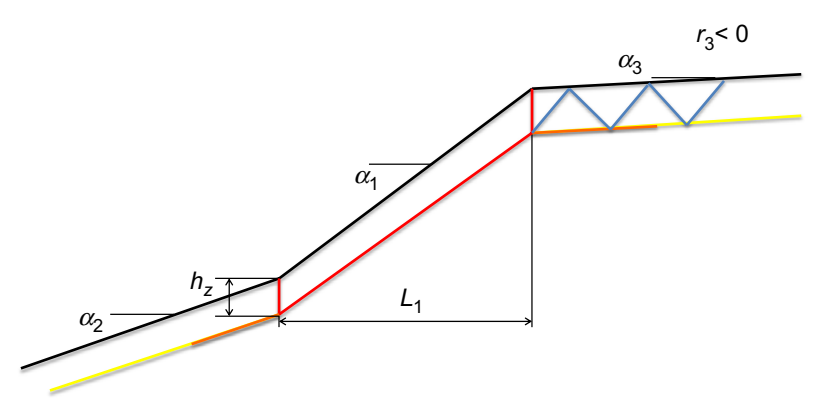

Fig. 5. Block mechanism of a spreading failure (simplified after Kvalstad et al., 2005)

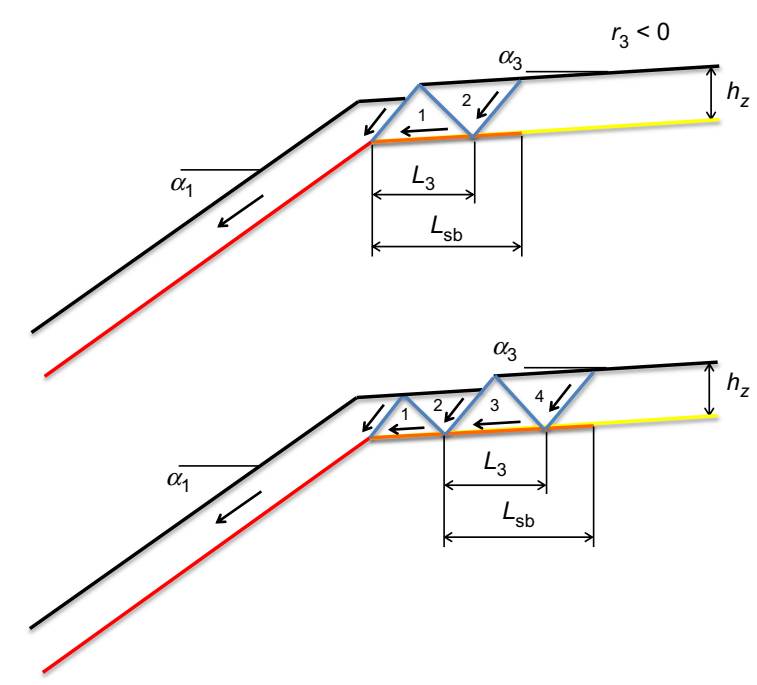

Fig. 6. Two consecutive frames describing the spreading failure mechanism: continuous removal of the material at the foot of the semi-infinite slope is driving SBP, causing failure of new active blocks (arrows show directions of the movement)

Kvalstad et al. (2005) did not justify this assumption, while in fact the inequality (11) is the key criterion for the assessment of the probability of the retrogressive failure, which is going to be derived below, after the phenomenon of the retrogressive SBP is investigated in the following section.

\section{RETROGRESSIVE SHEAR BAND PROPAGATION}

Retrogressive shear band propagation: problem formulation

Consider the problem of the post-earthquake retrogressive SBP at the depth $h_{z}$ parallel to the slope surface (Fig. 7). If retrogressive SBP takes place a short time after the earthquake, the pseudo-static earthquake-induced shear stress $\tau_{\mathrm{h}}$ becomes equal to zero, but the post-earthquake value of the degradation index $\delta_{\mathrm{d}}$ is not likely to decrease considerably compared to its earthquake value (Puzrin et al., 1995). The normal horizontal stress $\sigma_{x}$ will be taken as an average value of this stress over the thickness $h_{z}$ of the layer

$$
\sigma_{x}(x)=\frac{1}{h_{z}} \int_{0}^{h_{z}} \sigma_{x}(x, z) \mathrm{d} z
$$

Assume here that in an intact slope the average normal stress would be equal to $\sigma_{x}=p_{x 0}$.

Following beam approximations, which have been shown to be a reasonable assumption for the problems of shallow discontinuities propagating parallel to the surface of a half space (e.g. Palmer \& Rice, 1973; Zlatin \& Khrapkov, 1986; Viesca \& Rice, 2012), it is assumed that the principal axes are 


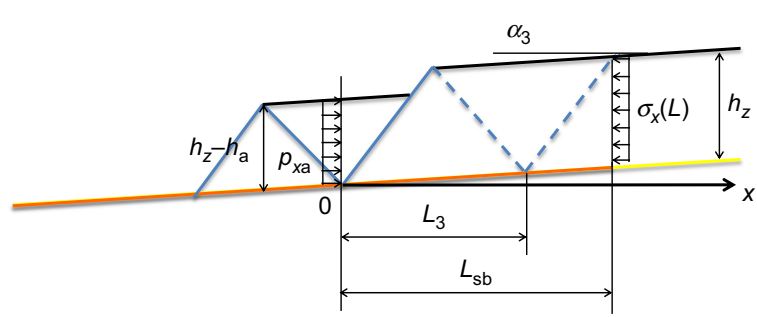

Fig. 7. Retrogressive SBP: problem formulation

parallel to the slope, so that

$$
\sigma_{x}(x)=\sigma_{\alpha}(x) \cos ^{2} \alpha_{3} \quad p_{x 0}=p_{0} \cos ^{2} \alpha_{3}
$$

where $\sigma_{\alpha}(x)$ is the principal average stress acting on a plane perpendicular to the slope surface subjecting a soil element to uniaxial compression; $p_{0}$ is the initial value of this stress.

At the bottom of the slope, soil failed in the active mode and its surface level dropped by $h_{\mathrm{a}}$. Therefore, the horizontal earth pressure at the bottom acting over the height $h_{z}-h_{\mathrm{a}}$ is the horizontal component $p_{x a}$ of the active pressure $p_{\mathrm{a}}$, which is a principal average stress acting on a plane perpendicular to the slope surface (beam approximation)

$$
p_{x \mathrm{a}}=p_{\mathrm{a}} \cos ^{2} \alpha_{3}
$$

This diminished support, together with the propagation of the shear band into the stable zone $\left(0>r_{3}\right)$, where the shear resistance $\tau_{\mathrm{r}}$ is higher than the gravitational shear stress $\tau_{\mathrm{g}}$, will cause the normal stresses in the layer above the band to drop below their initial value. From equilibrium of forces over the section $x$ of the body it follows

$$
\sigma_{x}(x)=p_{x \mathrm{a}} \frac{h_{z}-h_{\mathrm{a}}}{h_{z}}+\left(\tau_{\mathrm{r}}-\tau_{\mathrm{g}}\right) \frac{x}{h_{z}}
$$

where

$$
\tau_{\mathrm{g}}=\gamma^{\prime} h_{z} \sin \alpha_{3} \cos \alpha_{3}
$$

is the gravitational shear stress, while in the far field along the slope, the average stress asymptotically returns to the initial value $\sigma_{x}=p_{x 0}$. Of interest here is the maximum distance $L$ the shear band can propagate into the stable zone for the given value of $r_{\mathrm{a}}$.

\section{Material behaviour and kinematic assumptions}

The elasto-plastic relationship between the average horizontal normal stress $\sigma_{x}$ in the layer along the shear band and the average horizontal linear strain $\varepsilon_{x}$ is given by the linear elastic-perfectly plastic formula

$$
\begin{cases}\sigma_{x}=E_{\mathrm{u}} \varepsilon_{x}+p_{x 0}, & \text { for } \varepsilon_{x} \geq \frac{p_{x \mathrm{a}}-p_{x 0}}{E_{\mathrm{u}}} \\ \sigma_{x}=p_{x \mathrm{a}}, & \text { for } \varepsilon_{x}<\frac{p_{x \mathrm{a}}-p_{x 0}}{E_{\mathrm{u}}}\end{cases}
$$

where $p_{x a}$ is the average value of active lateral pressure in the layer, while $E_{\mathrm{u}}$ is the unloading plane strain modulus.

Here the case is considered where the end zone of the shear band is small compared to the thickness of the sliding layer. Displacements below the shear band are neglected, therefore the relative slide $\delta$ on the shear band will be equal to average displacements in the soil layer parallel to the slope surface $u_{\alpha}(x)$

$$
\delta(x)=u_{\alpha}(x)=\frac{u_{x}(x)}{\cos \alpha_{3}}=-\frac{1}{\cos \alpha_{3}} \int_{x}^{L} \varepsilon_{x}(\chi) \mathrm{d} \chi
$$

where $u_{x}(x)$ is the component of the average displacements in the soil layer parallel to the $x$ axis, given by integration of the average strain $\varepsilon_{x}$. Equation (18) is consistent with the fact that at the tip of the shear band $x=L$ the relative slide is zero.

The energy balance criterion for the SBP investigates the changes produced in the body by the shear band propagating by an increment of length $\Delta l$, parallel to the slope surface, with its horizontal component $\Delta L$ given by

$$
\Delta L=\Delta l \cos \alpha_{3}
$$

As a result of this incremental propagation the sliding layer experiences deformations at the end of the shear band leading to the displacement increment parallel to the slope

$$
\Delta \delta=-\varepsilon_{\alpha}(L) \Delta l
$$

where $\varepsilon_{\alpha}(x)$ is the principal average strain acting on a plane perpendicular to the slope surface (beam approximation)

$$
\varepsilon_{\alpha}(x)=\frac{\varepsilon_{x}(x)}{\cos ^{2} \alpha_{3}}, \quad \text { for } \tan ^{2} \alpha \ll 1
$$

Substituing equations (19) and (21) into (20) gives

$$
\Delta \delta=\frac{\Delta u}{\cos ^{3} \alpha_{3}}
$$

where

$$
\Delta u=-\varepsilon_{x}(L) \Delta L
$$

Horizontal and vertical components of the downslope displacement due to the incremental SBP are then obtained using equation (18)

$$
\begin{aligned}
& \Delta \delta_{x}=\Delta \delta \cos \alpha_{3}=\frac{\Delta u}{\cos ^{2} \alpha_{3}} \\
& \Delta \delta_{z}=\Delta \delta \sin \alpha_{3}=\frac{\Delta u}{\cos ^{2} \alpha_{3}} \tan \alpha_{3}
\end{aligned}
$$

\section{Energy balance approach: assumptions and calculations}

In this section a derivation of the SBP criterion for the problem in Fig. 7 is attempted directly from the energy balance, following Palmer \& Rice (1973). The main assumptions made in this analysis are that, in the absence of dilation in the shear band, most of the energy transfer during SBP will take place due to

(a) external work made by gravitational forces on downslope movements of the layer above the shear band

(b) internal work made by the normal stress acting parallel to the slope surface on deformations of the layer caused by changes in these stresses

(c) plastic work dissipated on the shear band.

Because the analyses are performed for post-earthquake conditions, inertial effects and kinetic energy acquired by the soil mass can be neglected. While the viscous component of soil behaviour and dissipation of the excess pore water pressures may affect the shear strength inside the shear band (e.g. Puzrin \& Randolph, 2015), adopting the shear strength values from field tests performed at large strains and fast rates close to those expected in the retrogressive SBP allows for these effects to be accounted for within the proposed simplified analysis.

The energy balance criterion for the post-earthquake SBP requires that the energy surplus produced in the body by propagation of the shear band by an increment of length $\Delta l$, parallel to the slope surface, should exceed the work required 
for this incremental propagation. Mathematically, this can be expressed as the following inequality

$$
\Delta W_{\mathrm{e}}-\Delta W_{\mathrm{i}}-\Delta D_{L} \geq \Delta D_{\omega}
$$

where

$$
\begin{aligned}
\Delta W_{\mathrm{e}} & =\gamma^{\prime} h_{z} L \Delta \delta_{z}-p_{\mathrm{a}}\left(h_{z}-h_{\mathrm{a}}\right) \cos \alpha_{3} \Delta \delta \\
& =\left[\tau_{\mathrm{g}} L-p_{x \mathrm{a}}\left(h_{z}-h_{\mathrm{a}}\right)\right] \frac{\Delta u}{\cos ^{4} \alpha_{3}}
\end{aligned}
$$

is the increment of the external work made in the present case by gravitational forces and active pressure on downslope movements of the layer above the shear band

$$
\begin{aligned}
\Delta W_{\mathrm{i}} & =h_{z} \Delta l \cos \alpha_{3} \int_{0}^{\varepsilon_{\alpha}(L)} \sigma_{\alpha}\left(\varepsilon_{\alpha}\right) \mathrm{d} \varepsilon_{\alpha} \\
& =\frac{h_{z} \Delta L}{\cos ^{4} \alpha_{3}} \int_{0}^{\varepsilon_{x}(L)} \sigma_{x}\left(\varepsilon_{x}\right) \mathrm{d} \varepsilon_{x}
\end{aligned}
$$

is the increment of the internal work made by the normal stress acting parallel to the slope surface on deformations of the layer caused by changes in these stresses

$$
\Delta D_{L}=\tau_{\mathrm{r}} l \Delta \delta=\tau_{\mathrm{r}} L \frac{\Delta u}{\cos ^{4} \alpha_{3}}
$$

is the increment of the plastic work dissipated on the shear band, which is required to overcome the residual shear resistance along the band

$$
\Delta D_{\omega} \approx \Delta l \int_{0}^{\delta_{\mathrm{r}}}\left[\tau(\delta)-\tau_{\mathrm{r}}\right] \mathrm{d} \delta=\frac{\Delta L}{\cos \alpha_{3}}\left(\tau_{\mathrm{p}}-\tau_{\mathrm{r}}\right) \bar{\delta}
$$

is the increment of the plastic work dissipated in the shear band during its propagation, which is required to overcome the shear resistance in excess of residual in the end zones of the band.

Expressions (26)-(29) after being substituted into inequality (25) yield a sufficient SBP condition for a general form of constitutive law

$$
\begin{aligned}
- & {\left[\left(\tau_{\mathrm{g}}-\tau_{\mathrm{r}}\right) L-p_{x \mathrm{a}}\left(h_{z}-h_{\mathrm{a}}\right)\right] \frac{\varepsilon_{x}(L) \Delta L}{\cos ^{4} \alpha_{3}} } \\
- & \frac{h_{z} \Delta L}{\cos ^{4} \alpha_{3}} \int_{0}^{\varepsilon_{x}(L)} \sigma_{x}\left(\varepsilon_{x}\right) \mathrm{d} \varepsilon_{x} \geq \frac{\Delta L}{\cos \alpha_{3}}\left(\tau_{\mathrm{p}}-\tau_{\mathrm{r}}\right) \bar{\delta}
\end{aligned}
$$

Energy balance criterion for the retrogressive shear band propagation

For the particular form of the constitutive law (17), and using equilibrium equation (15), after some mathematical elaboration inequality (30) reduces to

$$
\frac{E_{\mathrm{u}} h_{z}}{2}\left[\varepsilon_{x}(L)\right]^{2} \geq\left(\tau_{\mathrm{p}}-\tau_{\mathrm{r}}\right) \bar{\delta}
$$

and can be further transformed into

$$
\begin{aligned}
L \leq L_{\mathrm{sb}}= & -\frac{p_{0}-p_{\mathrm{a}} r_{\mathrm{a}}}{\tau_{\mathrm{p}}-\tau_{\mathrm{r}}} \frac{h_{z}}{r_{3}} \cos ^{2} \alpha_{3} \\
& +\frac{1}{r_{3}} \sqrt{\frac{2 E_{\mathrm{u}} h_{z} \bar{\delta} \cos ^{3} \alpha_{3}}{\tau_{\mathrm{p}}-\tau_{\mathrm{r}}}} ; r_{\mathrm{a}}=\frac{h_{z}-h_{\mathrm{a}}}{h_{z}}
\end{aligned}
$$

where, for post-earthquake conditions, the shear stress ratio equals

$$
r_{3}=\frac{\tau_{\mathrm{g}}-\tau_{\mathrm{r}}}{\tau_{\mathrm{p}}-\tau_{\mathrm{r}}}=\frac{s \chi \tan \alpha_{3}-1}{s-1}<0 ; \chi=\frac{1}{\delta k\left(1-r_{\mathrm{u}}\right)}
$$

Inequality (32) provides an estimate for the maximum length, $L_{\mathrm{sb}}$, which the retrogressive shear band can reach for a given value of $r_{\mathrm{a}}$. If this length satisfies inequality (11): $L_{\mathrm{sb}} \geq L_{3}$, retrogressive SBP will lead to spreading, even for $\alpha_{3}=0$.

\section{SPREADING FAILURE CRITERIA}

Estimate of the retrogressive shear band length

Equation (32) uses values of initial and active effective earth pressures, acting parallel to the slope surface, which are assumed to be principal stresses in order to allow for a beam approximation. Initial effective earth pressure (average over depth $h_{z}$ ) can be expressed by way of the normal effective stress $\sigma_{\mathrm{n}}^{\prime}$ acting perpendicular to the sliding surface

$$
\sigma_{\mathrm{n}}^{\prime}=\gamma^{\prime} \delta_{\mathrm{d}}\left(1-r_{\mathrm{u}}\right) h_{z} \cos ^{2} \alpha_{3}
$$

For the $K_{0}$ at rest earth pressure acting parallel to the slope, equations (5) and (6) give

$$
p_{0}=\frac{1}{2} K_{0} \sigma_{\mathrm{n}}^{\prime}\left[h_{z}\right]=\frac{1}{2 k} K_{0} \tau_{\mathrm{p}}\left[h_{z}\right]
$$

The active effective pressure can be estimated at failure as a function of the normal effective stress $\sigma_{\mathrm{n}}^{\prime}$ acting perpendicular to the sliding surface. It follows that by using equations (5) and (6), the average active pressure over depth $\left(h_{z}-h_{\mathrm{a}}\right)$ can also be expressed by way of $\tau_{\mathrm{p}}$ at the depth $h_{z}$

$$
\begin{aligned}
p_{\mathrm{a}} & =\frac{1}{2} \sigma_{\mathrm{n}}^{\prime}\left[h_{z}-h_{\mathrm{a}}\right]-\tau_{\mathrm{p}}\left[h_{z}-h_{\mathrm{a}}\right] \\
& =\tau_{\mathrm{p}}\left[h_{z}\right] r_{\mathrm{a}}\left(\frac{1}{2 k}-1\right)
\end{aligned}
$$

Substituting expressions (35) and (36) into (32), the estimate for the maximum length, $L_{\mathrm{sb}}$, is obtained

$$
\begin{aligned}
L_{\mathrm{sb}}= & -\frac{1 / k\left(K_{0}-r_{\mathrm{a}}^{2}\right)+2 r_{\mathrm{a}}^{2}}{1-1 / s} \frac{h_{z}}{2 r_{3}} \cos ^{2} \alpha_{3} \\
& +\frac{1}{r_{3}} \sqrt{\frac{s k_{E_{\mathrm{u}}} h_{z} \bar{\delta} \cos ^{3} \alpha_{3}}{s-1}}
\end{aligned}
$$

where

$$
k_{E_{\mathrm{u}}}=\frac{2 E_{\mathrm{u}}}{\tau_{\mathrm{p}}} ; r_{\mathrm{a}}=\frac{h_{z}-h_{\mathrm{a}}}{h_{z}} ; r_{3}=\frac{s \chi \tan \alpha_{3}-1}{s-1}
$$

\section{Estimate of the spreading failure block length}

The exact length of the spreading failure block $L_{3}$ depends on the kinematics of the failure mechanism, which is beyond the scope of this paper. From the Kvalstad et al. (2005) analysis it can be concluded that

$$
L_{3} \approx 2 h_{z} \cos ^{2} \alpha_{3}
$$

is a reasonable first approximation for the length of the spreading failure block, consistent with the limit analysis using the Tresca type failure criterion, which suggests that the failure planes should be inclined by $45^{\circ}$ to a principal axis.

\section{Critical depth of the sliding surface}

The criterion for spreading failure can be formulated in terms of the critical depth of the failure surface $h_{\mathrm{cr}}$ at which the sliding can take place. Indeed, substituting expressions (37)-(39) into (11) and resolving it with respect to depth $h_{z}$ gives the two necessary conditions for spreading to occur

$$
\left\{\begin{array}{c}
a_{\mathrm{a}}>0 \\
h_{z} \geq h_{\mathrm{cr}}=\frac{s k_{E_{\mathrm{u}}} \bar{\delta}}{(s-1) a_{\mathrm{a}}^{2} \cos \alpha_{3}}
\end{array}\right.
$$


where

$$
a_{\mathrm{a}}=2 r_{3}+\frac{1 / k\left(K_{0}-r_{\mathrm{a}}^{2}\right)+2 r_{\mathrm{a}}^{2}}{2(1-1 / s)}
$$

If either one of the conditions (40) is not satisfied, spreading is impossible.

\section{Critical drop in the failed seabed level as a function of} depth of the sliding surface

An alternative way to formulate the criterion for the spreading failure is in terms of the minimum drop of the failed seabed surface level $h_{\text {acr }}$ at which the sliding surface can develop at the depth $h_{z}$. Indeed, substituting expressions (37)-(39) into (11) and resolving it with respect to the drop $h_{\mathrm{a}}$ in the seabed surface gives the two necessary conditions for spreading to occur

$$
\left\{\begin{array}{c}
b_{\mathrm{a}} \geq 0 \\
h_{\mathrm{a}} \geq h_{\mathrm{acr}}=h_{z}\left(1-\sqrt{b_{\mathrm{a}}}\right)
\end{array}\right.
$$

where

$$
b_{\mathrm{a}}=\frac{4(1-1 / s) r_{3}+K_{0} / k-2 \sqrt{(s-1) k_{E_{\mathrm{u}}} \bar{\delta} /\left(s h_{z} \cos \alpha_{3}\right)}}{1 / k-2}
$$

is the retrogressive SBP parameter. If either one of the conditions (42) is not satisfied, spreading is impossible.

\section{CASE STUDY: SPREADING FAILURES IN PALAEO-LANDSLIDES}

The following case study validates the new spreading failure criteria against the observed Caspian Sea palaeolandslides MM700 and MM900 (Fig. 1, after Gray et al., 2015). Palaeo-landslide geometry has been reconstructed by assuming the seabed at the time of failure followed approximately the same inclination as the first continuous geophysical horizon beneath each landslide, but starting at the top of the landslide headwall. The approximation is supported by the occurrence of generally parallel/subparallel beds in the shallow section that have been folded to produce the anticline form, as observed on seismic data (Fig. 1).

\section{Evidence of a spreading failure in the palaeo-landslide MM700}

Spreading failure has been observed in a stable zone after the MM700 event (Fig. 1). The following geometric and soil parameters have been adopted for the landslide analysis based on the geophysical and geotechnical data obtained from in situ testing and laboratory analysis, following over two decades of geotechnical data acquisition to support the ACG development (see Hill et al., 2015)

$$
\begin{aligned}
& \alpha_{3}=0.55^{\circ} ; \quad h_{z}=185 \mathrm{~m} ; \quad h_{\mathrm{a}}=95 \mathrm{~m} ; \quad r_{\mathrm{a}}=90 / 185=0.486 \\
& k=0.21 ; \quad s=2.4 ; \quad \delta_{\mathrm{d}}=1.0 ; \quad r_{\mathrm{u}}=0 ; \\
& \chi=\frac{1}{1 \times 0.21 \times 1}=4.76 ; \quad k_{E_{\mathrm{u}}}=254 ; \quad K_{0}=0.6
\end{aligned}
$$

so that the shear stress ratio

$$
r_{3}=\frac{s \chi \tan \alpha_{3}-1}{s-1}=\frac{2.4 \times 4.76 \times 0.0096-1}{2.4-1}=-0.636
$$

For spreading to occur in the MM700 slide, both conditions (40) have to be satisfied, which is achieved for $\bar{\delta} \leq 0 \cdot 16 \mathrm{~m}$

$$
\left\{\begin{array}{c}
a_{\mathrm{a}}=0.617>0 \\
h_{z}=185 \mathrm{~m}>h_{\mathrm{cr}}=183 \mathrm{~m}
\end{array}\right.
$$

\section{Lack of evidence of a spreading failure in} palaeo-landslide MM900

In contrast to MM700, the MM900 shows no evidence of spreading upslope in the stable zone (Fig. 1; Gray et al., 2015). Gray et al. (2015) note that some spreading occurred along the steep initiation scarp base, although this was a later stage phenomenon after initial failure of the steep slopes (the subject of the current analysis). The following geometric parameters have been adopted for the landslide analysis

$$
\alpha_{3}=1.01^{\circ} ; \quad h_{z}=25 \mathrm{~m} ; \quad h_{\mathrm{a}}=25 \mathrm{~m} ; \quad r_{\mathrm{a}}=0
$$

while the soil parameters remain the same as in the MM700 analysis, so that the shear stress ratio:

$$
r_{3}=\frac{s \chi \tan \alpha_{3}-1}{s-1}=\frac{2.4 \times 4.76 \times 0.0176-1}{2.4-1}=-0.57
$$

and for $\bar{\delta} \geq 0.10 \mathrm{~m}$, corresponding to the thickness of the zone of intense shearing $h_{\mathrm{sb}} \geq 30 \mathrm{~mm}$, the first condition (40) is satisfied, while the second is not satisfied

$$
\left\{\begin{array}{c}
a_{\mathrm{a}}=1.308>0 \\
h_{z}=25 \mathrm{~m}<25.5 \mathrm{~m} \leq h_{\mathrm{cr}}
\end{array}\right.
$$

Therefore, the range of the values of parameter $\bar{\delta}=0 \cdot 10-0 \cdot 16 \mathrm{~m}$ allows for the observed presence and absence of spreading in the MM700 and MM900 landslides, respectively.

\section{Step in the palaeo-landslide MM700 sliding surface}

Finally, evidence of spreading failure is observed in the MM700 landslide in the stable zone along a sliding surface at the depth of $185 \mathrm{~m}$ below the original seabed (Fig. 1). This is $40 \mathrm{~m}$ above the shear band in the quasi-stable zone, which propagated unstably $225 \mathrm{~m}$ below the original seabed and caused the initial failure. Explanation of this step in the sliding surface is given below, using the same calibrated range of the values of parameter $\bar{\delta}=0 \cdot 10-0 \cdot 16 \mathrm{~m}$.

As the unstable shear band reaches the stable zone, the soil fails in active failure and the seabed surface level starts dropping (Fig. 8). For the retrogressive shear band to start propagating at the depth of the unstable shear band, this drop has to be sufficiently large. However, before reaching this drop, it is possible that a smaller drop can initiate retrogressive propagation at a higher level, which will cause a step in the sliding surface.

Criterion (42) for the spreading failure is formulated in terms of the minimum drop of the seabed surface level $h_{\text {acr }}$ at which the failure surface can develop at the depth $h_{z}$. Using this criterion, it is possible to determine $h_{\text {acr }}$ for both observed depth of the retrogressive SBP, $h_{z}=185 \mathrm{~m}$, and observed depth of the unstable SBP, $h_{z}=225 \mathrm{~m}$. Comparing these $h_{\text {acr }}$ with the observed drop in seabed surface $h_{\mathrm{a}}=95 \mathrm{~m}$, 


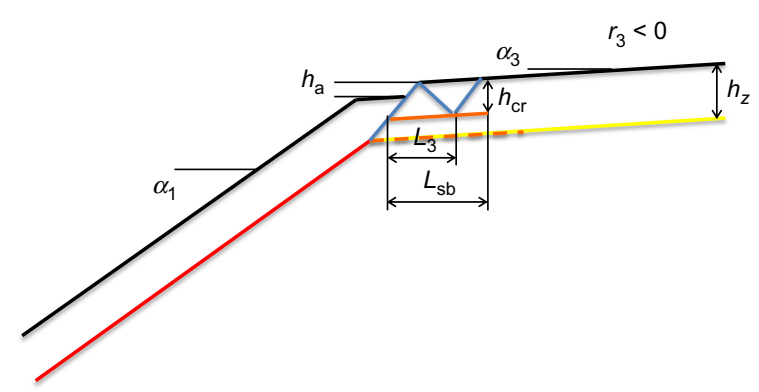

Fig. 8. Step between the unstable and the retrogressive shear bands

will help to determine which depth $h_{z}$ is admissible for the spreading failure.

In order to investigate the case of the original shear band depth, the following geometric parameters have been adopted for this analysis: $\alpha_{3}=0.55^{\circ} ; h_{z}=225 \mathrm{~m}$, while the soil parameters remain the same as in the MM700 analysis above. In this case the shear stress ratio remains as in equation (44) and the first condition (42) is satisfied, while the second is not satisfied

$$
\left\{\begin{array}{c}
b_{\mathrm{a}}=0 \cdot 262-0 \cdot 311 \geq 0 \\
h_{\mathrm{a}}=95 \mathrm{~m}<h_{\mathrm{acr}}=99-110 \mathrm{~m}
\end{array}\right.
$$

From equation (48) it follows that the drop of the seabed surface by $h_{\mathrm{a}}=95 \mathrm{~m}$ was insufficient to cause the shear band originally propagating unstably at the depth $h_{z}=225 \mathrm{~m}$ to continue to propagate retrogressively at the same depth.

In contrast, when the case of the observed shear band depth $h_{z}=185 \mathrm{~m}$ is investigated with all other parameters remaining the same, both conditions (42) become satisfied

$$
\left\{\begin{array}{c}
b_{\mathrm{a}}=0 \cdot 238-2.92 \geq 0 \\
h_{\mathrm{a}}=95 \mathrm{~m} \geq h_{\mathrm{acr}}=85-95 \mathrm{~m}
\end{array}\right.
$$

From equations (49) it follows, that the drop of the seabed surface by $h_{\mathrm{a}}=95 \mathrm{~m}$ was sufficient to cause the shear band to start propagating retrogressively at the observed depth $h=185 \mathrm{~m}$. Therefore, the range of the values of parameter $\bar{\delta}=0 \cdot 10-0.16 \mathrm{~m}$, calibrated above for the MM700 and MM900 palaeo-landslides is also consistent with the observed step in the sliding surface. Combined with the observed thickness of the sliding surface, which was estimated in the range of $3-5 \mathrm{~cm}$ from the extracted soil samples, the range of $\bar{\delta}=10-16 \mathrm{~cm}$ allows for back-calculating of the slip weakening shear strain (at which the shear strength drops to residual) of about $\gamma_{\mathrm{r}}=\delta_{\mathrm{r}} / d=10$. This value is consistent with the one adopted by Einav \& Randolph (2006) for soft marine clays and with the results of the field vane shear tests performed to support the ACG development (see Hill et al., 2015).

\section{SUMMARY AND CONCLUSIONS}

The paper proposes a mechanism for the development of submarine spreading failures, which combines the retrogressive SBP with a series of active block failures in the sliding layer above the shear band. This mechanism is only valid above the failed quasi-stable portion of the slope, that is, within the stable zone of the slope, where the gravitational shear stress is smaller than the residual shear strength. Gradual downhill removal of the failed material causes a decrease in the supporting pressure, leading to the progressive uphill propagation of the shear band (termed here retrogressive SBP) and uniquely determining its length. Only under such conditions will the pressures in the sliding body remain compressive and not get below the active earth pressure, allowing the length of the shear band to be linked to dimensions of the spreading failure blocks.

An energy balance based criterion has been formulated for spreading, in terms of the critical depth of the failure surface. For a given drop in the failed seabed surface level, it provides a minimum depth at which a retrogressively propagating shear band could reach sufficient length to enable development of spreading blocks. An alternative spreading failure criterion was formulated in terms of the minimum drop of the failed seabed level necessary for initiation of the failure blocks for a given depth of the retrogressive SBP.

Both criteria have been validated against the observed phenomena (presence and absence of the evidence of spreading failure for different landslide depths and a step in the sliding surface) in the Caspian Sea palaeo-landslides (MM700 and MM900), which allowed calibration of the values of characteristic displacement $\bar{\delta}=0 \cdot 10-0 \cdot 16 \mathrm{~m}$. This range appears to be rather tight, considering that the rest of the model parameters have been adopted directly from the field and laboratory studies without any additional adjustments. Combined with the observed thickness of the sliding surface, this range allowed for back-calculating of the slip weakening shear strain at which the shear strength drops to residual. The back-calculated values were consistent both with those suggested in the literature and with the results of the field vane shear tests performed to support the ACG development.

It seems that the proposed framework is capable of providing quantitative explanations of observed submarine spreading failure phenomena. Depending on the results of further numerical and field validation, the proposed criteria can be modified to include the shear band process zone, neglected by the energy balance approach, and to account for specific forms of spreading failure blocks and their dimensions. The important feature of the proposed framework, however, is that it can accommodate all these potential modifications and still provide closed-form criteria, which can be incorporated into a GIS based deterministic and probabilistic stability analysis for assessment of spreading failure risks in submerged slopes across offshore developments.

\section{ACKNOWLEDGEMENTS}

Valuable discussions with Ed Clukey (BP), Brian Mackenzie (Fugro), David Rushton (Fugro), Robert Viesca (Tufts University), Jim Rice (Harvard University), Denys Brunsden, Mark Lee and Andy Mills are highly appreciated.

\section{NOTATION}

$a_{\max }$ peak ground acceleration

$b_{\mathrm{a}}$ retrogressive SBP parameter

$C$ pseudo-static seismic factor

$E_{1} \quad$ plane strain deformation modulus in loading

$E_{\mathrm{u}}$ plane strain deformation modulus in unloading

$f(x)$ slope surface geometry

g gravitational acceleration

$h$ thickness of sliding layer

$h_{\mathrm{a}}$ drop in seafloor level

$h_{\text {acr }}$ critical drop in seafloor level

$h_{\mathrm{cr}}$ critical depth of failure surface at which sliding can take place

$h_{z} \quad$ depth of slip surface

$K_{0} \quad$ earth pressure coefficient at rest

$k$ undrained shear strength coefficient

$k_{E_{\mathrm{u}}} \quad$ normalised plane strain deformation modulus in unloading

$k_{\mathrm{h}} \quad$ pseudo-static coefficient

$L$ horizontal coordinate of tip of shear band 
$L_{\mathrm{cr}}$ horizontal component of critical length of shear band

$L_{\mathrm{i}}$ horizontal component of initial length of shear band

$L_{\mathrm{sb}}$ horizontal component of maximum length which shear band can propagate for a given drop in the seafloor surface

$L_{3}$ horizontal component of length of active/passive failure block

$l$ length of shear band

$M$ earthquake magnitude

$p_{\mathrm{a}} \quad$ average active failure pressure in sliding layer

$p_{\mathrm{p}}$ average passive failure pressure in sliding layer

$p_{x \mathrm{a}}$ horizontal component of average active failure pressure

$p_{x 0}$ horizontal component of average initial lateral pressure

$p_{0}$ average initial lateral pressure in sliding layer

$r$ shear stress ratio

$r_{\mathrm{a}}$ normalised drop in seafloor level

$r_{\mathrm{u}}$ normalised excess pore water pressure

$\bar{r}$ average shear stress ratio

$r_{3}$ shear stress ratio of upslope stable zone

$s$ sensitivity ratio between peak and residual shear strength

$u_{\mathrm{e}}$ excess pore water pressure

$\alpha$ slope angle

$\alpha_{3}$ slope angle of upslope stable zone

$\gamma$ shear strain within slip surface

$\gamma_{\mathrm{r}} \quad$ slip weakening shear strain at which shear strength drops to residual

$\gamma_{\mathrm{t}} \quad$ total unit weight of soil

$\gamma^{\prime} \quad$ submerged unit weight of soil

$\Delta D_{L} \quad$ increment of plastic work dissipated on shear band

$\Delta D_{\omega}$ increment of plastic work dissipated in end zone shear band

$\Delta L$ horizontal component of increment of shear band length $\Delta l$

$\Delta W_{\mathrm{e}} \quad$ increment of external work

$\Delta W_{\mathrm{i}}$ increment of internal work

$\Delta \delta \quad$ increment of relative displacement due to incremental SBP

$\delta$ relative displacement between boundaries of shear band

$\delta_{\mathrm{d}} \quad$ seismic degradation index

$\delta_{\mathrm{r}} \quad$ slip weakening length/displacement

$\bar{\delta} \quad$ characteristic displacement between boundaries of shear band

$\varepsilon_{x} \quad$ average horizontal strain in sliding layer

$\varepsilon_{\alpha} \quad$ average principal strain in sliding layer

$\sigma_{\mathrm{n}}^{\prime} \quad$ normal effective stress on sliding surface

$\sigma_{x}$ average horizontal normal stress in sliding layer

$\sigma_{\alpha} \quad$ average principal normal stress in sliding layer

$\tau_{\mathrm{g}} \quad$ gravitational shear stress

$\tau_{\mathrm{h}}$ pseudo-static earthquake-induced shear stress

$\tau_{\mathrm{p}} \quad$ undrained peak shear resistance of shear band

$\tau_{\mathrm{r}} \quad$ undrained residual shear resistance of shear band

$\chi$ coefficient defined in equation (6)

\section{REFERENCES}

Bjerrum, L. (1967). Progressive failure in slopes in overconsolidated plastic clay and clay shales. Terzaghi Lecture. J. Soil Mech. Found. Div., ASCE 93, No. 5, 3-49.

Boulanger, R. B. \& Idriss, I. M. (2004). Evaluating the potential for liquefaction or cyclic failure of silts and clays, Report No. UCD/ CGM-04/01. Davis, CA, USA: Center for Geotechnical Modeling, Department of Civil \& Environmental Engineering, University of California Davis.

Carson, M. A. (1977). On the retrogression of landslides in sensitive muddy sediments. Can. Geotech. J. 14, No. 4, 582-602.

Dey, R., Hawlader, B., Phillips, R. \& Soga, K. (2012). Effects of shear band propagation on submarine landslide. In Proceedings of the 22nd international offshore and polar engineering conference, Rhodes, Greece (eds J. S. Chung and W. C. Kan), vol. 2, pp. 766-772. Cupertino, CA, USA: International Society of Offshore and Polar Engineers (ISOPE).

Dimmock, P., Mackenzie, B. \& Mills, A. J. (2012). Probabilistic slope stability analysis in the West Nile Delta, offshore Egypt. In Offshore site investigation and geotechnics: integrated geotechnologies - present and future: Proceedings of the 7 th international conference (ed. P. G. Allan), pp. 535-542. London, UK: Society for Underwater Technology.

Einav, I. \& Randolph, M. F. (2006). Effect of strain rate on mobilised strength and thickness of curved shear bands.
Géotechnique 56, No. 7, 501-504, http://dx.doi.org/10.1680/ geot.2006.56.7.501.

Germanovich, L., Kim, S. \& Puzrin, A. M. (2016). Dynamic growth of slip surfaces in catastrophic landslides. Proc. R. Soc. Math., Phys. Engng Sci. 472, No. 2185, 20150758.

Gray, T., Puzrin, A. M. \& Hill, A. (2015). Application of the shear band propagation method to slope stability analysis of a palaeo-landslide in the Caspian Sea. Proceedings of the offshore technology conference, Houston, TX, USA, paper OTC-25869-MS.

Haflidason, H., Sejrup, H. P., Nygard, A., Mienert, J., Bryn, P., Lien, R., Forsberg, C. F., Berg, K. \& Masson, D. (2004). The Storegga slide: architecture, geometry and slide development. Mar. Geol. 213, No. 1-4, 201-234.

Hill, A. J., Prakash, A., Hampson, K. M., Gray, T. E., Rushton, D., Mackenzie, B. \& Puzrin, A. M. (2015). Geotechnical challenges in the Caspian Sea. Proceedings of the offshore technology conference, Houston, TX, USA, paper OTC-25988-MS.

Hynes-Griffin, M. E. \& Franklin, A. G. (1984). Rationalizing the seismic coefficient method, Miscellaneous Paper GL-84-13. Vicksburg, MS, USA: US Army Engineer Waterways Experiment Station.

Kovacevic, N., Hight, D. W. \& Potts, D. M. (2004). Temporary slope stability in London clay - back analyses of two case histories. In Advances in geotechnical engineering: the Skempton conference (eds R. J. Jardine, D. M. Potts and K. G. Higgins), vol. 2, pp. 842-855. London, UK: Thomas Telford Publishing.

Kovacevic, N., Hight, D. W. \& Potts, D. M. (2007). Predicting the stand-up time of temporary London Clay slopes at Terminal 5 , Heathrow Airport. Géotechnique 57, No. 1, 63-74, http://dx.doi. org/10.1680/geot.2007.57.1.63.

Kvalstad, T. J., Andresen, L., Forsberg, C. F., Berg, K., Bryn, P. \& Wangen, M. (2005). The Storegga slide: evaluation of triggering sources and slide mechanics. Mar. Petrol. Geol. 22, No. 1, 245-256.

Lo, K. Y. (1972). An approach to the problem of progressive failure. Can. Geotech. J. 9, No. 4, 407-429.

Lo, K. Y. \& Lee, C. F. (1973). Stress analysis and slope stability in strain-softening materials. Géotechnique 23, No. 1, 1-11, http://dx.doi.org/10.1680/geot.1973.23.1.1.

Locat, A., Leroueil, S., Bernander, S., Demers, D., Jostad, H. P. \& Ouehb, L. (2011). Progressive failures in eastern Canadian and Scandinavian sensitive clays. Can. Geotech. J. 48, No. 11, 1696-1712.

Locat, A., Jostad, H. P. \& Leroueil, S. (2013). Numerical modeling of progressive failure and its implications for spreads in sensitive clays. Can. Geotech. J. 50, No. 11, 961-978.

Masson, D. G., Harbitz, C. B., Wynn, R. B., Pedersen, G. \& Lovholt, F. (2006). Submarine landslides: processes, triggers and hazard prediction. Phil. Trans. R. Soc. A 364, No. 1845, 2009-2039.

Odenstad, S. (1951). The landslide at Sköttorp on the Lidan River, February 2, 1946. R. Swedish Inst. Proc. 4, 1-38.

Palmer, A. C. \& Rice, J. R. (1973). The growth of slip surfaces in the progressive failure of overconsolidated clay. Proc. R. Soc. London, A 332, No. 1591, 527-548.

Potts, D. M., Dounias, G. T. \& Vaughan, P. R. (1990). Finite element analysis of progressive failure of Carsington embankment. Géotechnique 40, No. 1, 79-101, http://dx.doi.org/10.1680/ geot.1990.40.1.79.

Puzrin, A. M. \& Germanovich, L. N. (2005). The growth of shear bands in the catastrophic failure of soils. Proc. R. Soc. Math. Phys. Engng Sci. 461, No. 2056, 1199-1228.

Puzrin, A. M. \& Randolph, M.F. (2015). Effects of pore water pressure dissipation on rate dependency of shear strength in localised failure of soils. Int. J. Numer. Analyt. Methods Geomech. 39, No. 10, 1045-1062.

Puzrin, A., Frydman, S. \& Talesnick, M. (1995). Normalized non-degrading behaviour of soft clay under cyclic simple shear loading. ASCE J. Geotech. Engng 121, No. 12, 836-843.

Puzrin, A. M., Germanovich, L. N. \& Kim, S. (2004). Catastrophic failure of submerged slopes in normally consolidated sediments. Géotechnique 54, No. 10, 631-643, http://dx.doi.org/10.1680/ geot.2004.54.10.631.

Puzrin, A. M., Saurer, E. \& Germanovich, L. N. (2010). A dynamic solution of the shear band propagation in submerged landslides. Granular Matter 12, No. 3, 253-265. 
Puzrin, A. M., Gray, T. \& Hill, A. J. (2015). Significance of the true non-linear slope geometry for catastrophic failure in submarine landslides. Proc. R. Soc. Math., Phys. Engng Sci. 471, No. 2175, 20140772.

Quinn, P. E., Diederichs, M. S., Rowe, R. K. \& Hutchinson, D. J. (2011). A new model for large landslides in sensitive clay using a fracture mechanics approach. Can. Geotech. J. 48, No. 8, $1151-1162$.

Quinn, P. E., Diederichs, M. S., Rowe, R. K. \& Hutchinson, D. J. (2012). Development of progressive failure in sensitive clay slopes. Can. Geotech. J. 49, No. 7, 782-795.

Rice, J. R. (1973). The initiation and growth of shear bands. In Plasticity and soil mechanics (ed. A. C. Palmer), pp. 263-274. Cambridge, UK: Cambridge University Engineering Department.

Richardson, S. E. J., Davies, R. J., Allen, M. B. \& Grant, S. F. (2011). Structure and evolution of mass transport deposits in the South Caspian Basin, Azerbaijan. Basin Res. 23, No. 6, 702-719.
Rushton, D., Gray, T. E., Puzrin, A. M. \& Hill, A. J. (2015). GISBased probabilistic slope stability assessment using shear band propagation. Proceedings of the offshore technology conference, Houston, TX, USA, paper OTC-25871-MS.

Vanneste, M., Sultan, N., Garziglia, S., Forsberg, C. F. \& L'Heureux, J. S. (2014). Seafloor instabilities and sediment deformation processes: the need for integrated, multidisciplinary investigations. Mar. Geol. 352, 183-214.

Varnes, D. J. (1978). Slope movement types and processes. In Landslide analysis and control (eds R. L. Schuster and R. J. Krizek), Special Report 176, pp. 12-33. Washington, DC, USA: Transportation Research Board, National Academy of Sciences.

Viesca, R. C. \& Rice, J. R. (2012). Nucleation of slip-weakening rupture instability in landslides by localized increase of pore pressure. J. Geophys. Res. 117, No. B3, B03104.

Zlatin, A. N. \& Khrapkov, A. A. (1986). A semi-infinite crack parallel to the boundary of the elastic half-plane. Soviet Physics Doklady 31, No. 12, 1009-1010. 